\title{
Goethe, Steiner e o nascimento da arte de curar antroposófica no início do século $\mathrm{xx}$
}

Goethe, Steiner and the Birth of Anthroposophical Medicine at the Beginning of the 20th Century

Goethe, Steiner et la naissance de l'art de soigner anthroposophique au début du XXème siècle

Madel T. Luz e Leandro David Wenceslau

\section{CpenEdition}

\section{Journals}

Edição electrónica

URL: http://journals.openedition.org/rccs/5046

DOI: $10.4000 /$ rccs. 5046

ISSN: 2182-7435

\section{Editora}

Centro de Estudos Sociais da Universidade de Coimbra

Edição impressa

Data de publição: 1 Setembro 2012

Paginação: 85-102

ISSN: 0254-1106

\section{Refêrencia eletrónica}

Madel T. Luz e Leandro David Wenceslau, « Goethe, Steiner e o nascimento da arte de curar antroposófica no início do século xx », Revista Crítica de Ciências Sociais [Online], 98 | 2012, colocado online no dia 06 junho 2013, criado a 19 abril 2019. URL : http://journals.openedition.org/rccs/5046 ; DOI : $10.4000 /$ rccs.5046

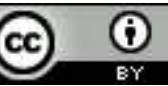




\section{MADEL T. LUZ, LEANDRO DAVID WENCESLAU}

\section{Goethe, Steiner e o nascimento da arte de curar antroposófica no início do século $x x$}

O artigo apresenta os principais elementos do pensamento científico goetheano
presentes no corpus teórico da racionalidade médica antroposófica, recente-
mente pesquisada por Luz e colaboradores. O método científico de Goethe
é apresentado pela identificação dos fenômenos primordiais, Ürphanomen,
constitutivos da essência das manifestações empíricas da natureza. Propõe-se
a superação da dicotomia entre ideia e experiência, indicando-se que toda cisão
no fenômeno é uma artificialidade portadora de obstáculos à plena compreensão
da natureza. A medicina antroposófica apresenta como traço fundamental de
sua cosmovisão padrões constitutivos da realidade. As chaves interpretativas
desses padrões são analisadas como fenômenos primordiais, nos moldes
goetheanos, de macrocosmo (universo) e microcosmo (ser humano), que
entram em estados dinâmicos de harmonia (saúde) ou desarmonia (doença).

Palavras-chave: antroposofia; Johann Wolfgang von Goethe, 1749-1832; medicina antroposófica; pensamento científico; Rudolf Steiner, 1861-1925.

\section{Introdução}

Ao longo do século xx, consolidou-se, de forma hegemônica, nos modos de interpretar e lidar com a saúde, adoecimento e cuidado humanos, um modelo teórico e prático de medicina que tem sido denominado modelo ou paradigma biomédico (Barros, 2008; Camargo Jr., 2003; Luz, 2005). Entre seus traços principais, destacam-se a redução da experiência de sofrimento físico e mental a alterações observáveis e mensuráveis no corpo humano, identificadas e rotuladas como patologias, assim como a presença de abordagens terapêuticas que também se limitam às vias físicas, químicas e biológicas de intervenção, consideradas mais eficazes e modernas. Entretanto, a partir da década de 70, fortaleceu-se no Brasil o interesse e o resgate de práticas de saúde que partem de princípios epistemológicos e culturais distintos da medicina científica, apontando para uma compreensão do humano não apenas como ser biológico, mas também psíquico, cultural, social e espiritual. 
Segundo Barros (2008), trata-se da estruturação de um paradigma contra-hegemônico ao modelo biomédico, denominado alternativo, que evoca conhecimentos sobre saúde, doença e terapêutica de antigos e novos sistemas que partem de uma compreensão integrada, holística do ser humano e do universo. Entre estes sistemas se destacam a medicina tradicional chinesa, a homeopatia e diversas terapias corporais, energéticas e alimentares, como o yoga e a macrobiótica, entre outros.

Todavia, enquanto sistema médico, a biomedicina se manteve com status hegemônico naturalizado nos discursos e práticas sociais, sendo as demais propostas terapêuticas rotuladas como não científicas e por isso, marginais tanto no ensino como nos serviços de saúde institucionalizados. Um marco crítico e propositivo na análise da medicina como fenômeno social foram os estudos, a partir da categoria racionalidade médica, empreendidos pelo grupo de pesquisa do CNPq Racionalidades Médicas, coordenado por Luz (Luz e Barros, 2012). O conceito de racionalidade médica foi desenvolvido por Luz como ferramenta teórica para contribuir com a pesquisa sociológica sobre a medicina e suas possíveis expressões na atualidade, elaborado aos moldes de um tipo ideal da sociologia weberiana. Um tipo ideal é uma categoria que descreve e interpreta um conjunto de fenômenos observáveis, de acordo com um modelo previamente definido, assinalado como portador de características empíricas ou traços teóricos localizáveis em intensidade variável no objeto em estudo ou no conjunto de fatos enquadráveis pelo conceito.

O conceito idealtípico de racionalidade médica é definido como todo o sistema médico complexo construído racional e empiricamente em cinco dimensões: uma morfologia humana (previamente definida como "anatomia"), uma dinâmica vital (previamente definida como "fisiologia"), uma doutrina médica (que define o que é estar doente ou sadio, o que é tratável ou curável, como tratar, etc.), um sistema diagnóstico e um sistema terapêutico (Luz, 2000). Posteriormente foi acrescentada a dimensão cosmologia, como fundamento das outras cinco dimensões. Assim, é possível o reconhecimento de modos diversos de se pensar e fazer medicina, com base em um referencial teórico que define minimamente o que caracteriza, sociologicamente, um conjunto de saberes e práticas propriamente médicos. A pesquisa destas seis dimensões foi realizada, ao longo dos últimos 20 anos, em diversos sistemas médicos como a própria biomedicina, hegemônica e naturalizada, mas também em outros sistemas ditos alternativos, complementares ou integrativos, como a homeopatia, a medicina tradicional chinesa, a medicina ayurvédica e, mais recentemente, a medicina antroposófica (Luz e Wenceslau, 2012). 
A medicina antroposófica (MA) consiste num conjunto de saberes e práticas que resultam da aplicação dos princípios da antroposofia à compreensão dos processos de saúde-adoecimento e ao desenvolvimento de propostas terapêuticas, preventivas e de promoção de saúde, complementares à medicina ocidental contemporânea. Atualmente, segundo a Internationale Vereinigung Anthroposophischer Ärztegesellschften (IVAA, Federação Internacional de Associações Médicas Antroposóficas), há cerca de 15000 médicos no mundo com algum tipo de formação em MA, exercendo-a em 67 países, principalmente na Europa, e estimam-se mais de um milhão de usuários (IVAA, 2011). No Brasil, a MA é uma prática médica reconhecida pelo Conselho Federal de Medicina, que integra a Política Nacional de Práticas Integrativas e Complementares, desde 2006, no Sistema Único de Saúde em diversas cidades brasileiras.

A antroposofia foi concebida pelo filósofo e educador Rudolf Steiner ${ }^{1}$ entre fins do século XIX e primeiro quarto do século XX. Apresenta-se tanto como abordagem filosófica, que propõe a integração entre aspetos objetivos e subjetivos do processo cognitivo, quanto como modelo de estudo empírico da natureza e do ser humano. Os elementos centrais do pensamento antroposófico derivam da recepção e desenvolvimento realizados por Steiner da obra científica do pensador e poeta alemão Johann Wolfgang Goethe (1749-1832). A identificação e análise destes elementos, bem como a sua aplicação no campo médico, são o objeto principal do estudo hermenêutico empreendido neste artigo. É reconstruído o percurso reflexivo de Steiner, que parte da crítica do pensamento científico moderno, fundamento epistemológico da medicina convencional, e encontra em Goethe as bases de outra Weltanschauung ou cosmovisão, que fornece os fundamentos para a elaboração de modelos interpretativos alternativos da fisiologia e do adoecimento humanos.

Ainda que pesquisas em torno das concepções científicas de Goethe (cf. Maar, 2006; Kestler, 2006) já tenham sido desenvolvidas, a obra de Steiner abre a possibilidade de usos práticos e passíveis de atualização das concepções, aparentemente abstratas e ultrapassadas, do método científico goetheano, destacando-se como contraponto à racionalidade biomédica. Através da atualidade do interesse em torno de práticas como a medicina antroposófica, observa-se a conexão de fenômenos sociais do presente no campo da saúde com uma matriz que se mostra ainda viva entre os fundamentos dos modos de pensar e agir contemporâneos: a cosmovisão romântica de Goethe.

${ }^{1}$ Rudolf Steiner nasceu em Kraljevec, atual Croácia, no ano de 1861. Faleceu em Dornach, Suíça, em 1925. 


\section{Fundamentos de uma medicina ampliada}

O marco inicial histórico da medicina antroposófica encontra-se nos cursos oferecidos por Steiner, na Alemanha e Suíça, entre 1920 e 1924, em que abordou as possíveis contribuições da antroposofia à ampliação da medicina como ciência e arte de curar. Nestes cursos, dirigidos principalmente a médicos e estudantes de medicina, um dos pontos de partida reflexivos frequentemente adotados por Steiner era a necessidade de mudanças na formação médica. Na perspectiva deste filósofo, ficava claro que o estudante de medicina deveria desenvolver outra forma de compreender o ser humano saudável e o ser humano doente, que não era possibilitada pelas "ciências naturais", termo com o qual era comum se referir à anatomia, fisiologia e biologia, em sua época. Ele inicia o primeiro de seus cursos com a seguinte afirmação:

Qualquer tema médico discutido hoje, contudo, sempre possui como seu outro polo e contexto prévio a maneira como as pessoas são preparadas para trabalhar no campo da medicina, através de seus estudos em anatomia, fisiologia e biologia geral. Esta preparação dá ao pensar dos estudantes de medicina um viés particular desde o começo, e é deste viés, acima de tudo, que precisamos nos afastar. (Steiner, 2010: 1, tradução nossa)

O rumo tomado pelas ciências naturais na transição entre os séculos XIX e xx é um dos temas que despertaram a preocupação de Steiner, tanto numa perspectiva crítica quanto propositiva. No início do século XX, a medicina se delineava como locus privilegiado de aplicação ao estudo do corpo humano de uma determinada forma de se fazer ciência, que reduzia tanto o adoecimento quanto a cura a mudanças identificáveis apenas pelos sentidos físicos humanos, passíveis de mensuração e quantificação (Wenceslau, 2011).

Steiner, todavia, propôs que o ser humano é constituído por três formas básicas de expressão: o corpo, a alma e o espírito. Ele não se refere a estes elementos como coisas ou entidades, mas como modos ou formas do humano se perceber a si mesmo e ao mundo.

Por corpo, entende-se o elemento pelo qual as coisas ao redor do homem se apresentam a ele [...]. Por alma deve-se entender o elemento pelo qual o homem associa as coisas ao seu próprio existir, sentindo nelas agrado e desagrado, prazer e desprazer, alegria e dor. Por espírito entende-se o que se revela nele quando, segundo a expressão de Goethe, ele contempla as coisas "como se fosse um ente divino". É nesse sentido que o homem consiste em corpo, alma e espírito. (Steiner, 2004b: 28) 
Assim, o humano é caracterizado pelo encontro de duas experiências: (1) a experiência de um mundo corpóreo, relacionado aos sentidos físicos, que the aparece como uma realidade, inicialmente autônoma e independente e (2) a experiência de um universo interno de pensamentos e de reações a partir da realidade, que se organizam em um mundo particular, a princípio, "paralelo" ao anterior. Estes dois mundos se apresentam ao homem num primeiro momento como separados ou desconectados, o que sinaliza outro traço fundamental da própria constituição humana, ao menos em um momento inicial: sua inquietação, seu descontentamento, diante desta experiência inicial de separação, de perceber-se desintegrado do mundo.

Esse muro divisório entre o eu e o mundo surge tão logo a consciência desperta. Mas sempre permanece o sentimento de que o homem pertence ao mundo, de que existe um nexo que une o eu e o mundo de que não somos um ente fora, mas sim integrados ao universo. Esse sentimento é responsável pela busca da superação da referida contraposição. Pode-se dizer que, no fundo, toda e qualquer aspiração cultural da humanidade se baseia na superação dessa contraposição. A história cultural é, pois, o resultado da incessante busca pela unidade entre o eu e o mundo. Religião, Arte e Ciência procuram, cada uma a seu modo, esse mesmo fim. (Steiner, 2000: 25)

Foi na obra de Johann Wolfgang von Goethe, um dos grandes poetas e pensadores da modernidade clássica, que Steiner, ainda estudante da Academia Politécnica de Viena, encontrou um pensamento sobre as ciências naturais em condições de dialogar com o percurso reflexivo que ele mesmo começava a desenvolver. Em 1882, Steiner foi convidado para editar, no contexto da Bibliografia Nacional Alemã, os escritos científicos de Goethe, acrescentando introduções e comentários subsequentes. Com esta atividade, lhe foi dada a possibilidade de, sistematizando uma abordagem científica até então dispersa, subentendida nos escritos do autor do Fausto, apresentar sua própria concepção de ciência que via totalmente identificada com a de Goethe (Steiner, 2006).

\section{À procura do Ürphanomen}

Antes de apresentar as análises propriamente de Steiner, cabe uma introdução geral ao pensamento científico de Goethe. Ao longo da modernidade, institui-se uma forma de discurso sobre o mundo natural e a própria experiência humana denominada racionalidade científica moderna ou, simplesmente, ciência moderna, que, em oposição às explicações metafísicas e religiosas do universo que vigoraram durante o medievo, propõe a razão humana como ordenadora do mundo, capaz de explicar, modificar e controlar a realidade, 
a partir do distanciamento, da fragmentação, da experimentação e da introdução de um discurso de causalidade lógica, linear e previsível no mundo (Luz, 2004). O desacordo com este modelo de ciência e a busca por outras formas de se compreender a natureza se tornaram uma das tarefas de Goethe, de forma integrada à sua vida artística e política, sendo uma das maneiras com que expressou sua Bildung, isto é, seu próprio impulso formativo.

A pesquisa e a reflexão sobre História Natural foram das principais atividades do pensador de Frankfurt, na medida em que experimentava a necessidade de se posicionar acerca da relação homem-natureza e da forma como a ciência de seu tempo a abordava (Goethe, 1997: 237-238). Há dois traços fundamentais da aproximação goetheana à natureza: o reconhecimento desta como uma unidade, viva, infinita, capaz de assumir inúmeras formas e expressões; e o lugar do ser humano como parte desta unidade, com quem ela "fala constantemente": "Em parte alguma emudece ou morre para o observador atento" (ibidem: 96). O mundo se coloca diante do homem sem princípio nem fim, e por isso, "não se poderá estabelecer nunca, nem definir até que ponto o espírito humano será capaz de penetrar seus próprios mistérios e os do mundo" (ibidem: 193, tradução nossa). A infinda tarefa humana para Goethe é compreender esta linguagem da natureza.

Mas como nos fala a natureza? Como o ser humano pode mergulhar em seus mistérios, onde estão as chaves para o seu próprio enigma interior? Foi buscando a forma mais adequada de responder a estas perguntas que Goethe construiu sua própria abordagem científica. Não se tratava de nada propriamente inventado por Goethe, mas alicerçado em aspectos do pensamento de Leibniz, Spinoza e Kant. Sua proposta possui traços tanto empiristas quanto idealistas, correntes do pensamento científico aparentemente inconciliáveis, mas que Goethe buscou sintetizar numa espécie de "idealismo empírico" ou "idealismo objetivo" (Nisbet, 1972).

Se a chave está na Natureza, Goethe será de início um pensador o menos afeito possível a pontos de partida abstratos. $\mathrm{O}$ contato com a natureza se dá através da experiência sensível; logo, é dela que temos de começar todo trabalho de compreensão da sua linguagem. Num primeiro momento, o homem observa os objetos a partir de um viés particular, que Goethe entende como natural e até indispensável se pensarmos que "todo o seu destino depende de gostar ou não deles, de o atraírem ou repelirem, de lhe serem úteis ou prejudiciais" (Goethe, 1997: 151, tradução nossa). Todavia, ao assumir esta busca do conhecimento e da harmonia, é preciso superar este modo de ver e de julgar as coisas, que "expõe o homem a milhares de erros que com frequência o humilham e lhe amargam a vida" (ibidem). Este seria um primeiro passo do método científico de Goethe: um movimento 
de não se deixar levar pela primeira impressão da realidade, que provavelmente está atrapalhada por esta tendência inicial de querer ver as coisas como se gostaria que elas fossem.

Em seguida, podemos começar a buscar o caminho do conhecimento propriamente dito, a que Goethe se refere como o caminho científico. Este é composto de duas ações: (1) observar os objetos da natureza em si mesmos e (2) observá-los em suas relações recíprocas. A possibilidade de reconhecer uma realidade em si mesma nos é dada por nossa percepção sensível, nossos sentidos físicos. Enquanto as relações que existem entre os elementos que me surgem da realidade, só posso perceber através do pensamento. Reside neste segundo momento o núcleo de toda a abordagem científica goetheana. O pensamento é entendido enquanto órgão de percepção e não como um filtro limitador da realidade. A ideia faz parte da realidade e pode ser observada pelo nosso pensar, que funciona como olhos da alma humana. Atendo-se à experiência dos sentidos físicos, jamais se encontrarão quaisquer sinais de unidade e de conexão na realidade, apenas fatos isolados, soltos.

Assim, o ser humano, ao mesmo tempo em que percebe o mundo, se depara com a vida que o permeia. Porém, apesar de ser difícil separar estes dois momentos, torna-se necessário dirigir nossa atenção cuidadosamente e de forma ordenada a cada um destes aspectos, para que o conhecimento possa se edificar de forma cada vez mais ampla, justamente para não cair no viés individual citado anteriormente. Goethe se torna um entusiasta tanto da experimentação detalhada e repetida, quanto da contemplação silenciosa e reverente do mundo. Para a ciência de Goethe, "a matéria não existe nem pode nunca ser eficaz sem o espírito, nem o espírito sem a matéria" (Goethe, 1997: 242, tradução nossa)

Os pensamentos nascem necessariamente da organização do nosso ser e, de certa forma, são eles que nos permitem alcançar a unidade da realidade. Mas como encontrar uma correlação verdadeira entre os elementos do mundo sensível e não cair em uma abstração particular? Para isso, Goethe propõe que este trabalho de dedução (Goethe, 1993a: 68) - de ver o todo nas partes, e não de construir o todo a partir das partes - deve ser mediado pela realização do maior número de experiências ou experimentos possível, sempre num sentido de complementaridade e com o maior detalhamento, somado a uma espécie de ascese interior, em que se deve ser o mais severo observador de si mesmo e desconfiar constantemente de si em seus esforços (Goethe, 1997: 152). Seguindo estes passos, poder-se-á realizar o que ele chamou de experiência superior (Goethe, 1997: 162), que permite ao pesquisador encontrar uma estrutura fundamental da cosmovisão 
goetheana: o Urphänomen ou fenômeno primordial. A melhor descrição deste processo se encontra também em sua Doutrina das Cores:

Nós os denominamos fenômenos primordiais, pois nada no mundo fenomênico lhes é superior; ao contrário, partindo deles é possível descer gradualmente até o caso mais comum da experiência cotidiana, invertendo, assim, a via ascendente feita até agora.

O fenômeno primordial é, pois, tal qual o apresentamos. (Goethe, 1993b: 90)

Goethe também dispôs como se pode alcançar o fenômeno primordial (Goethe, 1997: 173-174). Estes apontamentos são ainda retomados por Steiner para a compreensão da cosmovisão goetheana. Num primeiro momento, nota-se um fenômeno empírico, que "limita-se aos fatos considerados isoladamente" e é associado por Steiner ao empirismo comum - poderemos chamá-lo também de experiência pura (Steiner, 2004a: 32; 1984: 109). No segundo momento, há o fenômeno científico, em que se começa a inferir causas e relações entre os fenômenos, embora de forma limitada. Neste momento, enxergam-se conceitos isolados, resultantes da soma de experiências, como impressões fixas, ainda não em movimento. Este nível de conhecimento se alcança através de uma das faculdades de nosso pensar, chamada por Goethe e Steiner de Verstand, que pode ser traduzido por intelecto ou entendimento (Goethe, 1992: 219; Steiner, 1984: 109; 2004a: 63). Contudo o esforço de Goethe é justamente ultrapassar estas duas posturas iniciais polares:

Goethe vê no primeiro método e no segundo método apenas unilateralidades.

O empirismo comum é a ignorância grosseira, pois nunca se eleva acima de uma mera enumeração de casualidades; o racionalismo, por sua vez, ao interpretar o mundo fenomenal, vê causas e relações que nele não se encontram. [...] Ambos os caminhos, o empirismo comum e o racionalismo, são para Goethe pontos de transição que devem ser superados e nada mais. (Steiner, 1984: 109-110)

Assim, no terceiro momento, há o fenômeno puro, que se mostra como uma sucessão constante de fenômenos, sendo deduzido de dentro das próprias experiências como seu elemento unitário. Ele é alcançado pela Vernunft, razão ou compreensão, capaz não apenas de ver conceitos isolados, mas a sua integração, a Ideia. A ideia para Goethe é "aquilo que continuamente surge no âmbito do fenomenal e por isso se nos impõe como lei de todo o acontecer fenomênico" (Goethe, 1992: 219). Se os conceitos fazem as correlações das experiências sensíveis, a Ideia integra, no sentido de atravessar, perpassar, os conceitos. Ela é intuída como uma totalidade de uma 
sequência de atividades ininterruptas (Goethe, 1993a: 70). Este processo dedutivo e objetivo de Goethe, quando chega a este nível de percepção, pode ser chamado de Anschauen, que em algumas traduções é apresentado como intuir (Goethe, 1993a: 67) e em outras como ver ou contemplar (Steiner, 2004a: 18), no sentido de imaginação sensível (Goethe, 1997: 211).

Depara-se então com um procedimento cauteloso de gestação das intuições, a partir de um contato regular com as experiências, até chegar ao ponto original, "pregnante", o fenômeno primordial. Neste fenômeno, ocorre transformação, sem alteração da essência - ele é ao mesmo tempo universal e plural, o mesmo em transformação. Steiner o associa ao conceito aristotélico de enteléquia (Steiner, 1984: 58) e Goethe deixa claro que se trata de um impulso formativo, um nisus formativus (Goethe, 1997: 187-189), ou Bildung, conceito que, para ele, supera o de Gestalt:

O Alemão tem para o conjunto da existência de um ser real a palavra 'Forma' [Gestalt]. Com este termo ele abstrai do que está em movimento, admite que uma coisa consistente nos seus elementos seja identificada, fechada e fixada no seu caráter.

Mas se considerarmos todas as formas, em particular as orgânicas, descobrimos que não existe nenhuma coisa subsistente, nenhuma coisa parada, nenhuma coisa acabada; antes que tudo oscila, num movimento incessante. A nossa língua costuma servir-se e, com razão, da palavra 'Formação' [Bildung] para designar tanto o que é produzido como o que está em vias de o ser. (Goethe, 1993a: 68-69)

Como resultado principal desta abordagem da História Natural, que o Poeta chamou de Morphologie e que se pode, a partir da citação anterior, chamar de estudo da Bildung, Goethe encontra o processo da metamorfose. Nele, a Natureza "produz uma parte a partir da outra e apresenta as mais partes mais diferentes pela modificação de um único órgão" (Goethe, 1993a: 35). Neste percurso por desvendar os movimentos essenciais da vida, em que o pensar é de certa forma um fazer (Goethe, 1992: 98), Goethe procura desenvolver um método científico em conformidade com a Natureza (Goethe, 1997: 180). Aqui, não é o pesquisador que a transforma, mas, se há um processo de intervenção, podemos dizer que é da Natureza com o pesquisador.

Em todos os casos, o investigador atento tem de observar-se a si próprio e esforçar-se por se mostrar tão plástico no seu modo de ver como lhe aparecem plásticos os órgãos que ele vê, a fim de, em nenhum lado, se petrificar rudemente num modo de explicação qualquer e procurar, antes, escolher em cada caso o mais adequado dos olhares, o mais análogo possível ao acto de intuir [Anschanen]. (Goethe, 1993a: 61) 
O pensador de Frankfurt reconhecia nas experiências sensoriais uma fonte de conhecimento da realidade, mas entendia que esta realidade não era simplesmente moldada pela sensorialidade humana, mas incluía o universo dos pensamentos. Para Goethe, não ocorreria apenas uma reinserção dos pensamentos humanos na realidade cognoscível, mas a própria realidade seria uma espécie de fluir ininterrupto entre o mundo material e as experiências do universo interno humano. Ambos resultariam das mesmas forças formativas de caráter arquetípico. Goethe concorda com Kant que não podemos acessar uma realidade fora de nossas experiências, mas esta experiência está o tempo todo vinculada a um universo que não se reduz àquele alcançado por nossos sentidos físicos, mas que Goethe amplia, conecta a percepções não físicas, suprassensíveis (Goethe apud Steiner, 2006: 90), que podem ser acessadas por nosso pensamento.

\section{Aplicando o método de Goethe às ciências naturais}

Sobre a situação das ciências naturais em seu tempo, Goethe expressava uma grande preocupação pela tendência abstracionista que via predominar em seus rumos. Além desta tendência, o pensador de Frankfurt assistia a uma indiscriminada expansão da instrumentalização na pesquisa científica e ironizava a quantidade de parafernálias necessárias, por exemplo, para se repetir os experimentos cromáticos de Newton. Apesar de ser um defensor convicto da empiria, Goethe acreditava que o fenômeno também estava no próprio observador, já que a ideia faz parte da experiência, e por isso não haveria nenhum instrumento melhor do que o próprio homem com seus sentidos e pensamentos para conhecê-los:

Em si mesmo, o ser humano, na medida em que se serve de seus plenos sentidos, é o maior e mais exato aparelho físico que possa existir, e o maior infortúnio da física moderna é justamente que as experiências foram, por assim dizer, separadas do homem e que $[\ldots]$ pretende-se conhecer a natureza apenas pelo que os instrumentos artificiais revelam. (Goethe apud Benjamin, 2009: 147)

Goethe não defendia uma única forma de fazer ciência, mas ciências adaptadas às diversas expressões que a natureza apresentava. Rudolf Steiner captou as nuances desta abordagem científica goetheana e sistematizou de forma mais clara as diferenças de sua aplicação:

A cosmovisão de Goethe é a mais multifacetada que se possa imaginar. Ela parte de um centro situado na natureza unitária do Poeta, e sempre mostra a face que corresponde à natureza do objeto contemplado. $\mathrm{O}$ caráter unitário das atividades das 
forças espirituais reside na natureza de Goethe; o respectivo modo dessa atividade é determinado pelo objeto em questão. Goethe empresta do mundo exterior o modo de observação, e não o impõe. Contudo, o pensar de muitas pessoas só é eficaz de uma determinada maneira, servindo apenas para uma espécie de objetos; não é unitário como o de Goethe, e sim uniforme. (Steiner, 2004a: 27)

Steiner observou que o fenômeno primordial de Goethe, a que o fundador da antroposofia também se referiu como conceito (Steiner, 1984: 161), pode ser alcançado na pesquisa das ciências naturais de duas formas, dependendo de como se apresenta ao conhecimento humano: uma adequada ao mundo inorgânico e outra ao mundo orgânico. O mundo inorgânico se caracteriza pela ausência de um princípio ativo interno, logo, suas transformações, suas mudanças derivam da atuação de forças externas. Mas como se dão estas transformações? Seguindo o método goetheano, descobre-se que os fenômenos primordiais que regem o mundo inorgânico são leis naturais. A maneira como explicamos o que acontece com os seres no mundo inorgânico é por leis que lhes são exteriores. Porém, estas leis, estas conexões, só são captadas pelo pensar, nada na realidade sensível nos diz diretamente delas. Por exemplo, no estudo das cores, Goethe demonstrou que os fenômenos cromáticos são resultantes da associação e derivações da luz e do escuro (o escuro não é visto por Goethe apenas como ausência de luz, mas como um fenômeno primordial em si).

É na descoberta das leis naturais do mundo inorgânico que o componente da experiência sensorial (pura e científica) atuaria de forma mais sensível na mediação do conhecimento. Ao controlar as condições e variáveis de um experimento inorgânico, podemos identificar qual componente permanece o mesmo: "ele é experiência superior na experiência; é o fato fundamental ou fenômeno primordial.” (Steiner, 2004a: 82-83). Quando as condições são dadas novamente, o fato acontece. Steiner define esta lei natural:

Toda lei natural tem, portanto, a seguinte forma: quando este fato atua juntamente com aquele, surge determinado fenômeno... Seria fácil demonstrar que todas as leis naturais têm realmente esta forma: quando dois corpos de temperaturas diferentes se tocam, flui calor do mais quente para o mais frio, até que a temperatura de ambas seja a mesma; quando um líquido está contido em dois recipientes interligados, o nível em ambos os recipientes fica na mesma altura; quando um corpo se encontra entre uma fonte de luz e um outro corpo, projeta uma sombra sobre este último. Aquilo que em Matemática, Física e Mecânica constitui mera descrição deve ser, então, fenômeno primordial. (2004a: 82) 
Quando nos deparamos com o fenômeno da vida, acontece algo completamente distinto. Se, no caso do mundo inorgânico, é preciso atravessar os sentidos para chegar ao conceito, no mundo orgânico o conceito permeia a manifestação física. Há um princípio ativo manifesto, algo totalmente diferente da realidade não viva e que não resulta apenas de leis externas, mas que interage com suas próprias leis formativas com a realidade.

No mundo orgânico, o conceito não aparece de fora da manifestação sensorial, mas também não pode ser captado apenas sensorialmente de forma direta. "No devir da planta, contudo, vive algo que já possui uma semelhança remota com aquilo que, no espírito humano, surge como imagem dessa planta" (Steiner, 2006: 101). É dessa forma que Goethe consegue chegar à folha como órgão primordial de toda a planta, sendo os demais (flores, frutos) resultantes de suas metamorfoses; ou ao tipo animal, em suas pesquisas de osteologia e embriologia. Steiner utilizará a palavra tipo para se referir ao conceito tanto no mundo animal quanto vegetal (Steiner, 1984: 162). A ciência orgânica não é, como a inorgânica, uma pesquisa das distinções entre o que é genérico e o que é específico, mas surge da evolução de uma forma orgânica que origina outra (Steiner, 2004a: 92). Se o método que prevalece na ciência inorgânica, por excelência, é a experimentação demonstrativa, para se adequar à natureza orgânica, o método mais apropriado é a intuição ou juízo contemplativo (Steiner, 2004a: 96).

Tendo descrito estas aplicações, com base também no que o próprio Goethe concretizou em termos de pesquisa, Steiner elaborou a proposta de um uso original do método goetheano, que se tornou a base das suas próprias pesquisas filosóficas e científicas, isto é, de sua antroposofia. Steiner desenvolveu o uso do pensamento, como órgão de percepção, de intuição e não de análise. Utilizou-o como razão para captar o próprio universo espiritual do homem (Steiner, 1984: 162). Para Steiner, é possível ir além do que Goethe alcançou, isto é, contemplar as ideias só no mundo sensível. É possível contemplá-las em sua forma original no próprio universo interior do ser humano. No mundo da consciência humana, a Ideia é o fenômeno primordial. Da mesma maneira que no mundo orgânico, ela é forma e conteúdo. No entanto, no espírito humano, a Ideia é totalmente automanifesta, sem apresentar um substrato físico na sua expressão. Se sua manifestação não depende de nenhum fator externo, podemos dizer que as Ideias se apresentam de forma livre ao pensamento humano (Steiner, 1985: 64).

\section{Princípios goetheanos da medicina antroposófica}

Tendo-se delineado o pensamento de Goethe e evidenciado as suas principais influências sobre Steiner, apresentam-se condições para apontar suas 
principais contribuições no desenvolvimento da medicina antroposófica. Em estudo anterior (Luz e Wenceslau, 2012), os conceitos e ferramentas práticas que constituem a MA foram apresentados dentro das seis categorias do tipo ideal racionalidade médica. No presente estudo, identificam-se quatro dos elementos essenciais da racionalidade médica antroposófica alicerçados na obra científica de Goethe. São eles: a trimembração, a quadrimembração, a compreensão do processo saúde-doença-cura e a própria terapêutica antroposóficas.

\section{a) A trimembração}

Steiner percebeu, bastante goetheanamente, certo tipo da organização humana que constitui uma dos fundamentos do método antroposófico. Em sua Introdução geral à Anatomia Comparada, baseada na Osteologia, Goethe observa que todos os seres a partir de certo grau de evolução podem ser divididos em três partes: a cabeça, o tórax e o abdômen. A cabeça responde pelos órgãos dos sentidos e pelo controle nervoso dos movimentos; a parte do meio, o tórax, contém os órgãos da vida interior ou vida vegetativa, que agem de dentro para fora; enquanto no abdômen se concentram os órgãos da nutrição, reprodução e de secreção de líquidos pouco elaborados. Para Goethe, as diversas espécies animais e o homem expressam metamorfoses deste tipo anatômico fundamental e variam sempre no sentido de aumentar, reduzir ou fusionar alguma destas partes (Goethe, 1837: 28).

Pode-se reconhecer nestas três partes do tipo animal uma referência encontrada e aprofundada por Steiner, que contribuiu para sua trimembração do organismo humano nos sistemas neurossensorial, rítmico e metabólico-motor. Steiner, aplicando estes conceitos ao processo de adoecimento, pôde observar nestas situações uma metamorfose do estado saudável do ser humano. O adoecimento seria a contração ou expansão destes princípios morfológicos, uns sobre os outros, podendo ser classificados em dois grandes grupos: a inflamação, quando ocorre uma invasão do metabólico sobre o neurossensorial; e a esclerose, que resulta do processo inverso, isto é, o princípio neurossensorial prevalecendo sobre o metabólico.

\section{b) A quadrimembração}

A forma como Steiner sistematizou o método científico de Goethe implica no reconhecimento de três mundos, três formas de manifestação da Natureza: o mundo inorgânico, o mundo orgânico e o mundo da consciência (das Ideias). No mundo orgânico, Goethe reconheceu dois tipos fundamentais: um tipo vegetal e um tipo animal. $\mathrm{O}$ mundo da consciência se revela como constituinte particular do mundo humano. O homem é constituído pelos 
demais mundos (inorgânico e orgânico), mas ele os eleva a um grau superior de complexidade.

Se nos mundos mais complexos se encontram os princípios dos mundos menos complexos ou inferiores, encontrar-se-ão no homem os princípios formativos do mundo inorgânico, do mundo orgânico vegetal, do mundo orgânico animal e do mundo da consciência. Aqui se vê um forte embasamento para a quadrimembração steineriana que reconhece $o$ ser humano, constituído por quatro corpos ou organizações, como se tem preferido denominar na medicina antroposófica: a organização física, que representa a estrutura de base mineral, sensível do organismo humano, responsável pela tendência de se entregar às leis físicas da natureza; a organização etérica ou vital, que responde pelos fenômenos vitais humanos como crescimento, reprodução, formação orgânica, e por uma tendência que evita a degradação do organismo humano; a organização anímica ou astral, que introduz na entidade humana a criação de um microuniverso, delimitado em relação a toda natureza, com capacidade de percepção e de interação com o todo; a organização do Eu, que agrega às qualidades anteriores a autoconsciência, a capacidade de, além de perceber o mundo, perceber a si mesmo, e não apenas interagir, mas agir com autonomia, como automanifestação, em liberdade (Steiner, 2004a).

Nas situações patológicas, também se observam metamorfoses de cada uma destas organizações que constituem a entidade humana: desgaste da organização vital, excesso da organização anímica, afastamento da organização do Eu, são alguns dos termos utilizados pelos médicos antroposóficos para compreender as situações de adoecimento.

\section{c) Compreensão do processo saúde-adoecimento}

Como foi indicado através destes exemplos, pode-se ver que a Medicina Antroposófica se utiliza diretamente do método científico goetheano. Nos processos orgânicos que provocam situações de sofrimento ao homem, busca-se entender a disposição dos princípios formativos do organismo humano (seja através da trimembração, seja através da quadrimembração) que estão em constante metamorfose, sendo regidos tanto pelos processos de crescimento gradual, quanto pelos de polaridade.

A situação que habitualmente chamamos de saúde, de bem-estar, tem sua origem na organização vital, ela que, desde o reino vegetal, combate a tendência à degradação, à separação, à ausência de forma da organização física. O corpo etérico traz forma, estrutura e vida interna. No entanto, tanto a organização anímica quanto a do Eu, para se ligarem à organização vital, dependem, em certa medida, de um desgaste desta última. Criar um mundo 
particularizado, trazer consciência à vida, só pode ser feito a partir de uma metamorfose da própria vida, que deixa de dar forma ao mundo físico, para passar a dar vida ao mundo consciente, espiritual. É neste balanço entre a atuação dos quatro corpos que poderemos entender o que sucede a um ser humano saudável e a um doente.

Estar saudável ou doente dependerá do equilíbrio destas forças. Um excesso de atuação da organização anímica ou do Eu sobre o etérico gera um determinado tipo de adoecimento, resultante de um excessivo desgaste da organização vital. Por outro lado, a frouxidão da organização anímica e do Eu em relação à organização vital deixa o organismo humano, como um todo, ou em alguns de seus sistemas ou órgãos, entregues a um excesso de atuação das forças formativas da organização etérica, como no caso dos tumores, por exemplo. Assim devemos buscar a causa do adoecimento sempre num excesso de atuação ou afastamento quer do corpo astral, quer da organização do Eu (Steiner e Wegman, 2007: 9-21).

É importante frisar que uma pessoa saudável não resulta apenas da atuação do corpo etérico, mas de um equilíbrio dinâmico entre essas nossas forças de vida e de morte, lembrando que para nascer espiritualmente é necessário, neste caso, morrer um pouco.

\section{d) A terapêutica}

Por último, breves palavras à influência de Goethe na terapêutica antroposófica. Nada mais adequado ao pensamento do poeta alemão do que buscar o equilíbrio para o ser humano no equilíbrio da própria natureza. As medicações antroposóficas são pesquisadas buscando sinais destes quatro princípios formativos nos minerais, plantas e animais. Vale recordar que, por exemplo, a organização do $\mathrm{Eu}$, nestes três reinos, ou a organização anímica, no vegetal e no mineral, não atuam a partir de dentro, mas "de fora”, assim como a organização vital, em relação ao reino mineral. Como aprendemos no estudo do mundo inorgânico, isto não impede que reconheçamos as suas forças formativas, os seus fenômenos primordiais, estejam eles "fora" ou "dentro" da experiência sensível. É dessa forma que utilizamos o método goetheano na pesquisa dos medicamentos para cada caso específico de arranjo das quatro organizações.

$\mathrm{Na}$ medida em que assimila essas substâncias em seu organismo, por trás da digestão e do metabolismo, as organizações do ser humano interagem com os impulsos formativos das substâncias. Ocorre um despertar de forças que estavam enfraquecidas, ou uma redistribuição de forças que estavam deslocadas, ou o relaxamento de outras que estavam tensionadas. É nesta direção que o tratamento antroposófico leva às últimas consequências 
a meta da ciência goetheana: colocar, ambos, ser humano e natureza, em equilíbrio, mediante uma doce - às vezes, um pouco amarga - influência mútua (Goethe, 1992: 220).

Estes elementos goetheanos da medicina antroposófica apresentam duas características constitutivas, semelhantes a todas as racionalidades médicas não-biomédicas já estudadas: (1) o holismo, através do qual se afirma que o microcosmo como um todo (todos os seres vivos considerados em sua totalidade individual, inclusive os seres humanos) manifestam, em sua constituição e funcionamento, o macrocosmo, isto é, a complexa ordem presente no universo e sua harmonia; (2) o vitalismo, que estabelece que a vida nos seres vivos é antes de tudo movimento, mutação constante, e que a morte é a cessação deste movimento no plano físico.

\section{Conclusão}

O percurso epistemológico retratado neste trabalho delineou os principais fundamentos teóricos de uma racionalidade médica, que, mesmo com traços descontextualizados dos modelos hegemônicos de ciência e medicina, provoca reflexões em torno da possibilidade de outras formas de se fazer ciência e cuidado em saúde. A dualidade sujeito-objeto, que fundamenta a busca ocidental moderna pelo conhecimento da natureza, do ser humano e do universo, pretende ser superada pelo método científico goetheano, que busca uma integração não apenas intelectual, mas vivencial e artística entre o pesquisador e o foco de sua pesquisa. A possibilidade de uma ciência que traga harmonia interior ao ser humano em equilíbrio com a harmonia da própria natureza é a particularidade de destaque nesta abordagem. A ciência goetheana parece apontar mais um voltar-se a si mesmo como caminho de desenvolvimento e progresso do que um controle sobre os fenômenos naturais.

Em tempos em que a velocidade das descobertas científicas e suas implicações na vida em sociedade fogem ao alcance de um profundo e cuidadoso debate ético e político, voltar a Goethe permite depararmo-nos com as questões primeiras dos usos e possibilidades da ciência. Abre um espaço de liberdade diante de um modelo quase hermético e totalitário de produção de conhecimento e, consequentemente, de valores.

A pesquisa - teórica e empírica - de práticas em saúde que ofereçam cuidado e sentido à experiência de adoecimento, como a medicina antroposófica, é um fenômeno pulsante em nosso tempo, que empurra a reflexão filosófica e social, assim como o ensaio de novas terapêuticas, para além dos estreitos horizontes que o modelo da racionalidade científica moderna delineou para o conhecimento humano. Neste sentido também, 
uma revisão, e mesmo um retorno, a pensamentos como os de Goethe e Steiner nos dão pistas e fornecem perguntas que orientam na busca da ampliação e transformação da racionalidade que medeia nossas práticas sociais e culturais de cura.

\section{Referências bibliográficas}

Barros, Nelson Filice de (2008), A construção da Medicina Integrativa: um desafio para o campo da saúde. São Paulo: Hucitec.

Benjamin, Walter (2009), Ensaios reunidos: escritos sobre Goethe. São Paulo: Duas Cidades; Ed. 34.

Camargo Jr., Kenneth Rochel (2003), Biomedicina, saber e ciência: uma abordagem crítica. São Paulo: Hucitec.

Goethe, Johann Wolfgang von (1837), "Introduction générale a l'anatomie comparée basée sur l'ostéologie", in Johann Wolfgang von Goethe, Oeuvres d'histoire naturelle de Goethe: divers mémoires d'anatomie comparée, de botanique e de géologie. Paris: Ab. Cherbuliez et C. Libraires, 23-60.

Goethe, Johann Wolfgang von (1992), Máximas e reflexões. Lisboa: Guimarães Editores [2 $2^{a}$ ed.].

Goethe, Johann Wolfgang von (1993a), A metamorfose das plantas. Lisboa: Imprensa Nacional - Casa da Moeda.

Goethe, Johann Wolfgang von (1993b), Doutrina das cores. São Paulo: Nova Alexandria.

Goethe, Johann Wolfgang von (1997), "Segunda parte: teoria general de la naturaleza", in Johann Wolfgang von Goethe, Teoría de la naturaleza. Madrid: Editorial Tecnos, 139-251.

IVAA (Internationale Vereinigung Anthroposophischer Ärztegesellschften) (2011), Anthroposophic Medicine / Facts and Figures (October 2011). Consultado a 04.05.2012, em http://www.ivaa.info.

Kestler, Izabela Maria Furtado (2006), "Johann Wolfgang von Goethe: arte e natureza, poesia e ciência”, História, Ciências, Saúde - Manguinhos, 13 (suplemento), 39-54.

Luz, Madel T. (2000), "Medicina e racionalidades médicas: estudo comparativo conceitual da medicina ocidental contemporânea, homeopática, tradicional chinesa e ayurvédica", in Ana Maria Canesqui (org.), Ciências sociais e saúde para o ensino médico. São Paulo: Hucitec, 181-200.

Luz, Madel T. (2004), Natural, racional, social: razão médica e racionalidade científica moderna. São Paulo: Hucitec [2. ${ }^{\mathrm{a}}$ ed. revista].

Luz, Madel T. (2005), "Cultura contemporânea e medicinas alternativas: novos paradigmas de saúde no fim do século XX", Physis: Revista de Saúde Coletiva, 15(suplemento), 145-176. 
Luz, Madel T.; Barros, Nelson Filice (orgs.) (2012), Racionalidades e práticas integrativas em saúde. Rio de Janeiro: UERJ/IMS/LAPPIS.

Luz, Madel T.; Wenceslau, Leandro David (2012), “A medicina antroposófica como racionalidade médica”, in Madel Terezinha Luz e Nelson Filice de Barros (orgs.), Racionalidades e práticas integrativas em saúde. Rio de Janeiro: UERJ/IMS/LAPPIS, 185-216.

Maar, Jurgen Heirich (2006), "Goethe e a história da ciência”, Episteme (Porto Alegre), 11(23), 95-116.

Nisbet, Hugh Barr (1972), Goethe and the Scientific Tradition. London: Institute of Germanic Studies.

Steiner, Rudolf (2000), A filosofia da liberdade: fundamentos para uma filosofia moderna: resultados com base na observação pensante, segundo o método das ciências naturais. São Paulo: Ed. Antroposófica.

Steiner, Rudolf (1984), A obra cientifica de Goethe. São Paulo: Antroposófica.

Steiner, Rudolf (1985), Goethe's World View. Spring Valley, NY: Mercury Press.

Steiner, Rudolf (2004a), O método cognitivo de Goethe: linhas básicas para uma gnosiologia da cosmovisão goetheana. São Paulo: Antroposófica.

Steiner, Rudolf (2004b), Teosofia: introdução ao conbecimento supra-sensível do mundo e do destino bumano. São Paulo: Antroposófica [7. ${ }^{a}$ ed.].

Steiner, Rudolf (2006), Minha vida - Rudolf Steiner: a narrativa autobiográfica do fundador da Antroposofia. São Paulo: Antroposófica.

Steiner, Rudolf (2010), Introducing Anthroposophical Medicine: Twenty Lectures Held in Dornach, Switzerland March 21 - April 9, 1920. Great Barrington, MA: Anthroposophic Press.

Steiner, Rudolf; Wegman, Ita (2007), Elementos fundamentais para uma ampliação da arte de curar. São Paulo: Antroposófica.

Wenceslau, Leandro David (2011), Por uma medicina que eduque, por uma pedagogia que cure: as contribuições de Rudolf Steiner à integralidade na educação médica. Dissertação de mestrado em Educação, Programa de Pós-graduação em Educação, Universidade Federal de Pernambuco, Brasil. 